\title{
Vitamin D in Musculoskeletal Health and Beyond
}

\author{
Terry J. Aspray ${ }^{1,2,3}$
}

Published online: 8 January 2020

(c) Springer Science+Business Media, LLC, part of Springer Nature 2020

It is 100 years since Mellanby first hypothesised that a fat soluble antirachitic factor cured rickets in puppies [1] and, in this edition of Calcified Tissue International, the effects of this steroid nutrient/pro-hormone, later named vitamin $\mathrm{D}$, on many systems of the body are reviewed. Vitamin D is important in calcium homeostasis and deficiency states are associated with rickets, osteomalacia and myopathy, while other effects (some contested) on immunomodulation and non-musculoskeletal organ function are also considered.

Fraser et al. move us from the tentative characterisation of Mellanby's antirachitic factor in the early twentieth century to the identification of a number of biomarkers of vitamin D status, with serum (or plasma) 25 hydroxyvitamin D $(25(\mathrm{OH}) \mathrm{D})$ as our go-to marker of vitamin D status. Although the harmonisation of mass spectrometry with immunoassays for its measurement remains a challenge, using LC-MS/MS methods, a range of vitamin D metabolites can be measured, including 1,25 dihydroxyvitamin D $\left(1,25(\mathrm{OH})_{2} \mathrm{D}\right)$ and 24,25 dihydroxyvitamin $\left(24,25(\mathrm{OH})_{2} \mathrm{D}\right)$. The clinical role of new assays is not clear, although the ratio of $25(\mathrm{OH}) \mathrm{D}$ to $24,25(\mathrm{OH})_{2} \mathrm{D}$ presents an example, where 24-hydroxylase deficiency is indicated in infantile hypercalcaemia [2]. Professor Cashman's agrees that $25(\mathrm{OH}) \mathrm{D}$ is the best biomarker defining vitamin D status [3]. However, the development of public health policy on vitamin D nutrition is a challenge. The National Academy of Medicine (NAM, formally the Institute of Medicine (IOM)) and the UK Scientific Advisory Committee on Nutrition (SACN) use threshold for circulating $25(\mathrm{OH}) \mathrm{D}$ predicting osteomalacia risk [4, 5], while alternative strategies lead to recommended daily

Terry J. Aspray

Terry.Aspray@Newcastle.ac.uk

1 NIHR Newcastle Biomedical Research Centre, Campus for Ageing and Vitality, Newcastle upon Tyne NE4 5PL, UK

2 The Bone Clinic, Freeman Hospital, Newcastle Upon Tyne Hospitals Trust, Newcastle upon Tyne NE7 7DN, UK

3 Translational and Clinical Research Institute, Newcastle University, Newcastle upon Tyne NE2 4HH, UK vitamin D intakes ranging from $400 \mathrm{IU}[4,5]$ to $2000 \mathrm{IU}$ [6]. How can dietary change influence vitamin D status? Should we take vitamin D supplements or can foodstuffs by routinely supplemented and should we promote sun exposure for cutaneous synthesis of vitamin $\mathrm{D}$ ? These questions are public health matters which may need to be addressed politically!

Vitamin D deficiency rickets appears to be increasing in the Americas, Europe and parts of the Middle East [7] and Moon et al. present an excellent overview of the consequences of maternal and childhood vitamin D deficiency [8]. They highlight significant physiological changes in pregnancy in vitamin D binding protein (DBP) and circulating levels of $1,25(\mathrm{OH})_{2} \mathrm{D}$ as well as the impact of maternal vitamin D deficiency on obstetric outcomes, such as gestational blood pressure and glucose homeostasis. In addition to rickets, they consider the impact of vitamin D status on bone mineral density (BMD), neonatal hypocalcaemia, and wider health concerns including birthweight and skeletal development in infancy and childhood.

Girgis reminds us that vitamin D is not just about bone, as he reviews its effects on the morphology and function of muscle [9]. Thresholds for 25(OH)D may be as low as $20 \mathrm{nmol} / \mathrm{L}$ for optimal calcium homeostasis, which is critically important to avoid muscle dysfunction. The effects of vitamin $\mathrm{D}$ on muscle strength, accelerated muscle ageing and impairment of muscle repair are reviewed, particularly in animal studies. However, mechanisms of action remain controversial, as the vitamin D receptor (VDR) is only found in very small amounts in muscle tissue, although Girgis and colleagues recently showed that myocyte-specific vitamin $\mathrm{D}$ receptor (mVDR) null mice, with no myocyte VDR whatsoever, still had altered muscle size and decreased strength [10]. There is also some complementary human research, including functional MRI studies showing evidence of improved mitochondrial function with vitamin D supplementation [11].

The potential immunomodulatory effects of vitamin D in vitro are well recognised and Harrison et al. describe their potential impact in vivo, particularly in rheumatoid arthritis 
[12]. They present a delightfully clear figure reminding the reader of the immune mechanisms under consideration. Vitamin D metabolites cause immune modulation as seen in diseases such as type 1 diabetes, Crohn's disease and rheumatoid arthritis. However, the clinical evidence is inconsistent and they recommend work on the metabolome should include circulating vitamin D analytes including the inflamed joint. The therapeutic questions remain whether vitamin D could and should be used to treat inflammatory arthritis, how it might work and who might benefit most? Complementing the theme of inflammation, Maes et al. look at the impact of vitamin D on infection in pulmonary disease [13]. They present epidemiological evidence of vitamin D deficiency in chronic lung disease and the therapeutic effects of vitamin D. They also suggest therapeutic mechanisms for which readers may find Fig. 1 from Harrison's article on rheumatoid arthritis helpful! There is also evidence of benefit in cystic fibrosis and asthma and a recent individual participant data (IPD) meta-analysis may be surprising, as vitamin $\mathrm{D}$ therapy decreased acute respiratory infections in a study recruiting participants aged $0-95$ years, although it was not possible to evaluate separately upper versus lower respiratory infections [14].

In vitamin D research, as elsewhere, no sooner have manuscripts been accepted for publication than the latest (sometimes contradictory) evidence is published. With large studies and meta-analyses, recruiting ever more diverse populations and looking at variable outcome measures, we are grateful to Dr Sami and Professor Abrahamsen for their attempts to keep us up to date [15]. They note a change in focus of vitamin D research. For example, we saw a number of studies in the 1990s on fracture prevention and the role of calcium, which are still extremely influential in practice today. However, the field has expanded to consider vitamin $\mathrm{D}$ with or without calcium with skeletal and/or non-skeletal outcomes in a range of populations: adult, old or very old. Coming back to public health concerns, the benefits of vitamin D supplements are relatively meagre when given to the many and we should recognise there are risks to a few, particularly the very old or frail who may succumb to adverse outcomes. We have also seen recent mega-trials which have failed to show significant effects on primary outcomes but may contribute enormously to further IPD meta-analyses. More work for someone in the near future, it appears!

\section{Compliance with Ethical Standards}

Conflict of interest Terry J. Aspray has no conflict of interest to declare.

\section{References}

1. Mellanby E (1920) Discussion on the importance of accessory food factors (vitamines) in the feeding of infants. Proc R Soc Med. 13(Sect Study Dis Child):95-98

2. Fraser WD, Tang JCY, Dutton JJ, Schoenmakers I (2019) Vitamin D measurement, the debates continue, new analytes have emerged, developments have variable outcomes. Calcif Tissue Int. https:// doi.org/10.1007/s00223-019-00620-2

3. Cashman KD (2019) Vitamin D deficiency: defining, prevalence, causes and strategies of addressing. Calcif Tissue Int. https://doi. org/10.1007/s00223-019-00559-4

4. Institute of Medicine (US) (2011) Committee to Review Dietary Reference Intakes for Vitamin D and Calcium. In: Ross AC, Taylor CL, Yaktine AL, Del Valle HB (eds) Dietary Reference Intakes for Calcium and Vitamin D. National Academies Press, Washington (DC). http://www.ncbi.nlm.nih.gov/books/NBK56070/. Accessed 4 Dec 2019

5. The Scientific Advisory Committee on Nutrition (SACN) Vitamin D and health report. In: GOV.UK. https://www.gov.uk/gover nment/publications/sacn-vitamin-d-and-health-report. Accessed 9 July 2019

6. Holick MF, Binkley NC, Bischoff-Ferrari HA (2011) Evaluation, treatment, and prevention of vitamin D deficiency: an endocrine society clinical practice guideline. J Clin Endocrinol Metab 96:1911-1930. https://doi.org/10.1210/jc.2011-0385

7. Creo AL, Thacher TD, Pettifor JM (2016) Nutritional rickets around the world: an update. Paediatr Int Child Health 37:84-98. https://doi.org/10.1080/20469047.2016.1248170

8. Moon RJ, Davies JH, Cooper C, Harvey NC (2014) Vitamin D, maternal and child health. Calcif Tissue Int. https://doi. org/10.1007/s00223-019-00560-x

9. Girgis CM (2019) Vitamin D and skeletal muscle: emerging roles in development, anabolism and repair. Calcif Tissue Int. https:// doi.org/10.1007/s00223-019-00583-4

10. Girgis CM, Cha KM, So B (2019) Mice with myocyte deletion of vitamin $\mathrm{D}$ receptor have sarcopenia and impaired muscle function: myocyte VDR mice have impaired muscle function. J Cachexia Sarcopenia Muscle. https://doi.org/10.1002/jcsm.12460

11. Sinha A, Hollingsworth KG, Ball S, Cheetham T (2013) Improving the vitamin D status of vitamin D deficient adults is associated with improved mitochondrial oxidative function in skeletal muscle. J Clin Endocrinol Metab 98:E509-E513. https://doi. org/10.1210/jc.2012-3592

12. Harrison SR, Li D, Jeffery LE, Raza K, Hewison M (2019) Vitamin D, autoimmune disease and rheumatoid arthritis. Calcif Tissue Int. https://doi.org/10.1007/s00223-019-00577-2

13. Maes K, Serré J, Mathyssen C, Janssens W, Gayan-Ramirez G (2019) Targeting vitamin D deficiency to limit exacerbations in respiratory diseases: utopia or strategy with potential?. Calcif Tissue Int. https://doi.org/10.1007/s00223-019-00591-4

14. Martineau AR, Jolliffe DA, Greenberg L (2019) Vitamin D supplementation to prevent acute respiratory infections: individual participant data meta-analysis. Health Technol Assess 23:1-44. https://doi.org/10.3310/hta23020

15. Sami A, Abrahamsen B (2019) The latest evidence from vitamin D intervention trials for skeletal and non-skeletal outcomes. Calcif Tissue Int. https://doi.org/10.1007/s00223-019-00616-y

Publisher's Note Springer Nature remains neutral with regard to jurisdictional claims in published maps and institutional affiliations. 